\title{
Does Fetal Fibronectin Predict the Delivery Route in Nulliparous Women at Postterm Induced by Dinoprostone?
}

\author{
Hale GOKSEVER CELIK¹, Engin CELIK², Gonca YETKIN YILDIRIM¹
}

Istanbul, Turkey

\begin{abstract}
OBJECTIVE: Digital cervical evaluation has been used to determine the likelihood of vaginal delivery which is considered by many women to be non-tolerable. Recently, alternative approaches such as transperineal ultrasound, fetal fibronectin test in cervicovaginal secretions have been investigating for the prediction of the delivery route. We aimed to study whether the usefulness of qualitative fetal fibronectin test in cervicovaginal secretions for the prediction of vaginal delivery in pregnant women at postterm induced with dinoprostone.
\end{abstract}

STUDY DESIGN: A total of 32 nulliparous pregnant women at postterm were enrolled in this prospective observational study. Fetal fibronectin test was applied to all participated women before the induction with dinoprostone and transvaginal ultrasonography was performed to measure cervical length.

RESULTS: The women having positive fetal fibronectin test result gave birth through vaginal route, except one case. Although there is no statistically significant difference, the shorter cervical length was associated with vaginal delivery in our population.

CONCLUSION: Fetal fibronectin test has a predictive value for delivery route in nulliparous women at postterm. Fetal fibronectin test may be used as a "rule out" test because the rate of fetal fibronectin positivity was found to be higher in patients who gave birth via vaginal route. As also shown in our study, although there is no statistically significant difference, the pregnant women with shorter cervical length might have a high possibility to achieve vaginal delivery.

Key words: Cervical length, Fetal fibronectin, Vaginal delivery

Gynecol Obstet Reprod Med 2020;26(2):83-87

${ }^{1}$ Saglik Bilimleri University Istanbul Kanuni Sultan Suleyman Training and Research Hospital Department of Obstetrics and Gynecology, Istanbul Turkey

${ }^{2}$ Istanbul University Faculty of Medicine Department of Obstetrics and Gynecology, Istanbul Turkey

Address of Correspondence: Hale Goksever Celik, Saglik Bilimleri University Istanbul Kanuni Sultan Suleyman Training and Research Hospital, Department of Obstetrics and Gynecology

34303 Istanbul, Turkey

hgoksever@yahoo.com

Submitted for Publication: $\quad$ 08.01.2019

Accepted for Publication: $\quad 18.02 .2019$

ORCID IDs of the authors: EC:0000-0001-7646-6091,

HGC:0000-0002-5162-3262,

GYY: 0000-0002-0091-0421

\begin{tabular}{|c|c|}
\hline \multirow{3}{*}{ 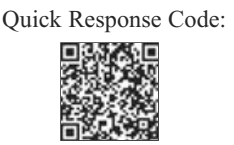 } & Access this article online \\
\hline & $\begin{array}{l}\text { Website: www.gorm.com.tr } \\
\text { e- mail: info@gorm.com.tr }\end{array}$ \\
\hline & DOI:10.21613/GORM.2018.880 \\
\hline
\end{tabular}

How to cite this article: Goksever Celik H. Celik E. Yetkin Yildirim G. Does Fetal Fibronectin Predict the Delivery Route in Nulliparous Women at Postterm Induced by Dinoprostone? Gynecol Obstet Reprod Med. 2020; 26(2):83-87

\section{Introduction}

The rate of incidence of cesarean section is steadily increasing all over the world in recent years. The most important point is the distinction between necessary and unnecessary cesarean sections. Because postponing the decision of cesarean section could cause undesirable results for the baby and the mother herself. On the other hand, unnecessary cesarean section should be avoided because of its associated risks and complications. Therefore, prediction of delivery route has been assessed in studies to prevent these associated poor outcomes.

The Bishop score including digital assessment of cervical dilatation and effacement, fetal descent, the position and consistency of the cervix has been used to evaluate the labor progress and determine the likelihood of vaginal delivery. But all parameters in this score are subjective, inconsistent and the score itself is associated with infections in recurrent vaginal examinations. Transperineal ultrasound examination allowing direct visualization of the fetal skull has been using widespread to evaluate the progress of labor in recent years (1). 
This examination is applicable to all pregnant women with low inter- and intra-observer variability. Fetal fibronectin $(\mathrm{fFN})$ is a glycoprotein which allows the adhesion between decidua and chorion (2). When the interface between fetal membranes and uterine wall disrupt, fFN begins to be detectable in cervicovaginal secretions. So the studies showed that its detection in cervicovaginal secretions is related to the onset of preterm labor $(3,4)$. There are many publications reporting that fFN is a well-tolerated test by pregnant women and it has a higher diagnostic accuracy than digital cervical examinations in the prediction of preterm birth at gestational ages from $22+0$ to $35+0$ weeks $(5,6)$.

In our study, we aimed to investigate whether qualitative $\mathrm{fFN}$ test is a predictive test for delivery route in nulliparous women at postterm induced with dinoprostone independent of the time required or the indication for cesarean section.

\section{Material and Method}

A total of 32 nulliparous women at postterm were enrolled in this prospective cohort study from August 2015 to July 2016. Our facility is a large tertiary care center, providing care for practically all of the region's obstetric population, particularly those with complicated pregnancies, administering around 15.000 births per year, with a cesarean delivery rate of $40 \%$. Our hospital's Ethics Committee approved our study which was in accordance with the Declaration of Helsinki (diary number 2015.14.7). All participated women were informed about the study and gave written informed consent.

The pregnant women at gestational age less than 41 weeks and the pregnant women having dilatation greater than $3 \mathrm{~cm}$ were excluded from our study. Multiparous pregnant women, the women with multiple pregnancies, fetal anomalies, previous uterine surgery and/or ruptured membranes or labor pain and the fetuses with the occiput posterior position and the presentation other than longitudinal cephalic presentation and the presence of cervical cerclage were also excluded.

Clinical and demographic characteristics of the patients were obtained from the patient. Gestational age was calculated from the last menstrual period and confirmed from the first trimester ultrasonographic measurement of the fetus. Body mass index (BMI) was calculated by measuring the weight and height of the patient on admission.

All participated women were examined before the admission to delivery unit in the supine position with flexed knees and hips and with an empty bladder. Fetal fibronectin determination in cervicovaginal secretions was performed on admission in all patients. Fetal fibronectin test is a qualitative test for the detection of $\mathrm{fFN}$ in cervicovaginal secretions which provides a positive or negative result based on a threshold of $50 \mathrm{ng} / \mathrm{mL}$. The secretion was collected using a vaginal swab which is placed in a tube with $1 \mathrm{~mL}$ extraction buffer.
Then test strip was placed into the tube for 10 minutes. The double lines were interpreted as positive result. It is important that the test should be performed before digital examination to prevent false positive results.

All ultrasonographic examinations were done by the same obstetrician using a Voluson 730 Expert with a $3.5 \mathrm{MHz}$ convex transabdominal probe. The transabdominal transducer was used to assess fetal biometric measurements, fetal position, habitus and placental location. A transvaginal probe was used to evaluate cervical length.

After the ultrasonographic evaluation, the cervical status was assessed digitally by the obstetrician in the delivery unit. Bishop score is used to determine the stage of labor before and after the induction which is a quantitative means of describing the cervical status to decide the necessity of cervical ripening agents. The parameters in this score are cervical dilatation and effacement, the position and consistency of the cervix and the station of the fetal head. All women in our study having Bishop score lower than 5 were induced with dinoprostone (Propess ovule; Ferring Medical, Istanbul, Turkey). The obstetrician evaluating patients with ultrasonography was not involved during follow-up in delivery unit. The birth attendants were blinded about the ultrasonographic measurements and fFN test results of the patients. All patients were monitored with non-stress test continuously. The obstetrician in the delivery unit decided on the delivery mode based on clinical assessment of the patient.

Statistical Analysis. Data are demonstrated as mean \pm SD for normally distributed continuous variables and frequencies for categorical variables. Relevant parameters were examined separately by appropriate chi-square test or independent samples t-test depending on the parameter type and their relationship with the delivery method. Statistical Package for Social Sciences (SPSS) for Windows version 22.0 (SPSS Inc., Chicago, IL, USA) was used for the analysis and two-sided $p$ value of $<0.05$ was considered as significant.

\section{Results}

A total of 32 nulliparous women who met the criteria were enrolled in our study. The mean gestational age was $41.0 \pm 0.3$ weeks. The mean age of patients in the study was $26.6 \pm 5.4$ years and the mean BMI was $28.5 \pm 4.0 \mathrm{~kg} / \mathrm{m}^{2}$. The clinical and laboratory characteristics of the patients are summarized in table 1 . All women in the study were nulliparous. They had a vaginal delivery rate of $43.8 \%$. The mean duration of Propess ovule application was $14.5 \pm 8.0$ hours. The leading reason for cesarean section was obstructed labor and fetal distress. (61.1\% and $38.9 \%$, respectively).

When the women were analyzed according to delivery route, the only statistically significant difference between vaginal birth group and cesarean section group was fFN test 
results. Women with positive fFN test results gave birth through vaginal route $(85.7 \%)$, whereas women with negative fFN test results underwent cesarean section (68\%) $(p=0.011)$. Although there is no statistically significant difference, women with shorter cervical length have a higher possibility for vaginal birth (Table 2).

\section{Discussion}

This study was designed to evaluate the usability of fFN in the prediction of delivery route in nulliparous women at postterm induced by dinoprostone. The decision for cesarean section at the right time to allow appropriate interventions about

Table 1: Clinical and demographic characteristics of the patients

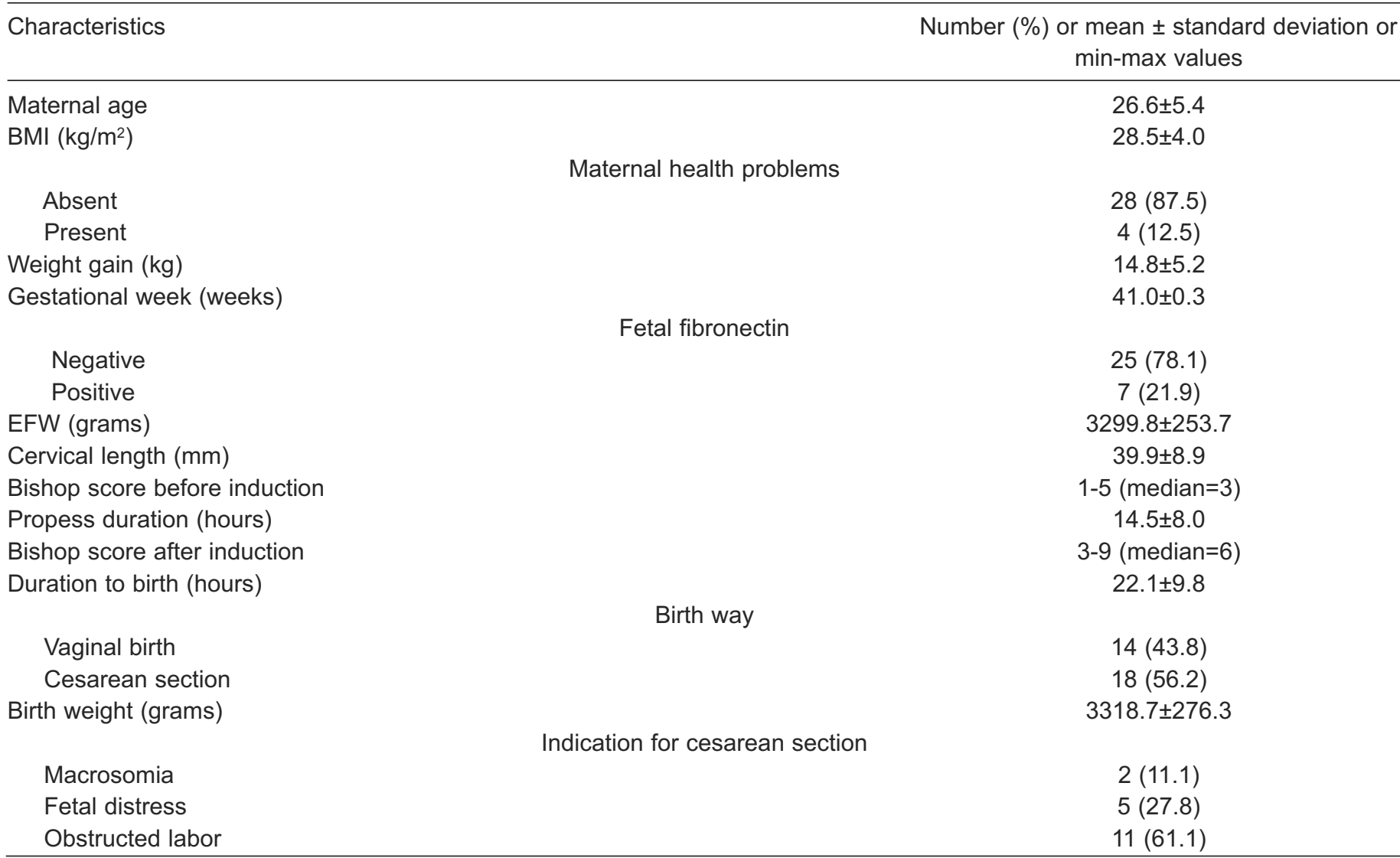

BMI: Body mass index, EFW: Estimated fetal weight

Table 2: Comparison of women according to delivery route

\begin{tabular}{lccc}
\hline Characteristics & Vaginal birth $(\mathrm{n}=14)$ & Cesarean section $(\mathrm{n}=18)$ & $\mathrm{p}$ value \\
\hline Age & $25.8 \pm 5.3$ & $27.3 \pm 5.6$ & $\mathrm{NS}$ \\
$\mathrm{BMI}\left(\mathrm{kg} / \mathrm{m}^{2}\right)$ & $28.2 \pm 4.6$ & $28.8 \pm 3.6$ & $\mathrm{NS}$ \\
Weight gain $(\mathrm{kg})$ & $15.3 \pm 5.3$ & $14.4 \pm 5.2$ & $\mathrm{NS}$ \\
Gestational week & $41.2 \pm 0.3$ & $41.0 \pm 0.3$ & $\mathrm{NS}$ \\
& Fetal fibronectin & & $\mathbf{1}$ \\
$\quad$ Negative & $8(32)$ & $17(68)$ & $\mathbf{0 . 0 1 1}$ \\
Positive & $6(85.7)$ & $3318.1 \pm 265.7$ & $\mathrm{NS}$ \\
EFW (grams) & $3276.3 \pm 245.1$ & $41.2 \pm 9.3$ & $\mathrm{NS}$ \\
Cervical length (mm) & $38.4 \pm 8.6$ & 3 (median value) & $\mathrm{NS}$ \\
Bishop score before induction & 3 (median value) & $15.9 \pm 9.8$ & $\mathrm{NS}$ \\
Propess duration (hours) & $12.8 \pm 4.8$ & 5 (median value) & $\mathbf{0 . 0 0 1}$ \\
Bishop score after induction & 7 (median value) & $24.1 \pm 12.1$ & $\mathrm{NS}$ \\
Duration to birth (hours) & $19.6 \pm 5.0$ & $3346.7 \pm 305.1$ & $\mathrm{NS}$ \\
Birth weight (grams) & $3282.9 \pm 240.7$ & & \\
\hline
\end{tabular}

BMI: Body mass index, EFW: Estimated fetal weight 
the mother and the baby is important. Accurate prediction of vaginal delivery especially in nulliparous women is very difficult. Because the digital cervical examination is unreliable, subjective and inconsistent and prone to high number of errors in the evaluation between the obstetricians. Therefore there is a need for a more objective and comfortable test for pregnant women to predict vaginal delivery.

We studied the utility of qualitative fFN test for the prediction of vaginal delivery on the nulliparous women who had unengaged head with low Bishop score and induced with dinoprostone. The unengaged head is not the only indication for cesarean section, but these women should be observed cautiously for a cesarean possibility. Induction stimulates the uterine contractions before the spontaneous onset of the labor. Some studies found that induction increased the rate of cesarean section compared with the spontaneous labor (7). The response to induction was examined with the Bishop score for many years which does not have a direct relationship with the vaginal delivery $(8,9)$.

Fetal fibronectin test is a very useful and effective test to identify patients who will be at risk for preterm delivery in symptomatic women. It is not useful in asymptomatic women as a predictive routine test $(10,11)$. The application of this test in symptomatic women reduce costs with the avoidance of unnecessary treatments and hospital admissions $(12,13)$. We hypothesized that fFN may be a useful marker to predict delivery route in nulliparous women at postterm based on the knowledge about its usefulness in the prediction of preterm delivery. The detection fFN in cervicovaginal secretions is a marker for disruption of choriodecidual interface which could provide a clue for the delivery route favoring the vaginal birth (14). It has a high negative predictive value and an excellent "rule out" test for preterm delivery (15). We also found that the negative fFN results were associated with cesarean delivery. So we should be careful in women with negative fFN results because of higher risk for cesarean section.

There are publications comparing the predictive strength of qualitative and quantitative fFN measurements $(16,17)$. A recent study showed that quantitative fFN test alone is equal effective to the combination of cervical length and qualitative fFN test (18). Although there is no statistically significance, the shorter cervical length was correlated with the higher likelihood of vaginal birth according to our results. But ultrasound measurement of the cervical length may become to be preferred more widely in future with further studies.

Vaginal bleeding was found as the only external factor reducing the validity of fFN test in the prediction of preterm delivery (19). So we excluded the women with vaginal bleeding or membrane rupture.

The superiority of our study is the first study investigating the utility of fFN for the prediction of vaginal delivery in nul- liparous women at postterm induced with dinoprostone. There are publications determining the value of pre-induction assessment of cervical FFN in the prediction of successful vaginal birth between 36 to 42 gestational weeks (20). Our limitation is the small number of cases and further studies in a larger population should be conducted for the prediction of labor route with $\mathrm{fFN}$ assessment supporting our results. In our results, the high rate of cesarean section may be criticized. But it should not be forgotten that nulliparous women at postterm induced with dinoprostone with Bishop score less than 5 were studied.

As a conclusion, fFN yields useful information identifying the pregnant women at low risk for cesarean section and so unnecessary interventions could be avoided. There is no still objective method to predict the likelihood of vaginal delivery. We believe that alternative methods which are better tolerated for women will be developed for the prediction of delivery route. Fetal fibronectin as one of these alternative methods should be investigated in further studies to help us for clinical decision of delivery route.

Acknowledgments: None

Conflict of interest: The authors declare no conflict of interest. Funding: None

Author contribution: HGC: The conception and design of the study, or acquisition of data, or analysis and interpretation of data, drafting the article or revising it critically for important intellectual content, final approval of the version to be submitted. EC: The conception and design of the study, or acquisition of data, or analysis and interpretation of data. GYY: The conception and design of the study, or acquisition of data.

\section{References}

1. Eggebo TM, Wilhelm-Benartzi C, Hassan WA, Usman S, Salvesen KA, Lees CC. A model to predict vaginal delivery in nulliparous women based on maternal characteristics and intrapartum ultrasound. Am J Obstet Gynecol. 2015;213(3):362.e1-6.

2. Bruijn MM, Vis JY, Wilms FF, Oudijk MA, Kwee A, Porath MM, et al. Comparison of the Actim Partus test and the fetal fibronectin test in the prediction of spontaneous preterm birth in symptomatic women undergoing cervical length measurement. Eur J Obstet Gynecol Reprod Biol. 2016;206:220-4.

3. Magro-Malosso E, Seravalli V, Cozzolino M, Spitaleri M, Susini T, Di Tommaso M. Prediction of preterm delivery by fetal fibronectin in symptomatic and asymptomatic women with cervical length $\leq 20 \mathrm{~mm}$. J Matern Fetal Neonatal Med. 2017;30(3):294-7.

4. DeFranco EA, Lewis DF, Odibo AO. Improving the screening accuracy for preterm labor: is the combination of fetal fibronectin and cervical length in symptomatic patients a useful predictor of preterm birth? A systematic review. Am J Obstet Gynecol. 2013;208(3):233.e1-6. 
5. Zhou MX, Zhou J, Bao Y, Chen YQ, Cai C. Evaluation of the ability of cervical length and fetal fibronectin measurement to predict preterm delivery in asymptomatic women with risk factors. J Matern Fetal Neonatal Med. 2015;28(2):153-7.

6. Bruijn M, Vis JY, Wilms FF, Oudijk MA, Kwee A, Porath $\mathrm{MM}$, et al. Quantitative fetal fibronectin testing in combination with cervical length measurement in the prediction of spontaneous preterm delivery in symptomatic women. BJOG. 2016;123(12):1965-71.

7. Shaikh F, Shaikh S, Shaikh N. Outcome of primigravida with high head at term. J Pak Med Assoc.2014;64(9): 1012-4

8. Bahadori F, Ayatollahi H, Naghavi-Behzad M, Khalkhali $\mathrm{H}$, Naseri Z. Predicting factors on cervical ripening and response to induction in women pregnant over 37 weeks. Med Ultrason. 2013; 15(3):191-8.

9. Meijer-Hoogeveen M, Roos C, Arabin B, Stoutenbeek P, Visser GH. Transvaginal ultrasound measurement of cervical length in the supine and upright positions versus Bishop score in predicting successful induction of labor at term. Ultrasound Obstet Gynecol. 2009; 33(2):213-20.

10. Esplin MS, Elovitz MA, Iams JD, Parker CB, Wapner RJ, Grobman WA, et al. Predictive accuracy of serial transvaginal cervical lengths and quantitative vaginal fetal fibronectin levels for spontaneous preterm birth among nulliparous women. JAMA. 2017;317(10):1047-56.

11. Dudley D. Serial transvaginal cervical length measurements and quantitative vaginal fetal fibronectin concentrations did not predict spontaneous preterm birth in low-risk nulliparous women. Evid Based Med. 2017;22(5):188.

12. Melchor JC, Navas H, Marcos M, Iza A, De Diego M, Rando D, et al. Predictive performance of PAMG-1 vs fFN test for risk of spontaneous preterm birth in symptomatic women attending an emergency obstetric unit: retrospective cohort study Ultrasound Obstet Gynecol. 2018; 51(5):644-9.

13. van Baaren GJ, Vis JY, Wilms FF, Oudijk MA, Kwee A,
Porath MM, et al. Cost-effectiveness of diagnostic testing strategies including cervical length measurement and fibronectin testing in women with symptoms of preterm labor. Ultrasound Obstet Gynecol. 2018;51(5):596-603.

14. Tripathi R, Tyagi S, Mala YM, Singh N, Pandey NB, Yadav P. Comparison of rapid bedside tests for phosphorylated insulin-like growth factor-binding protein 1 and fetal fibronectin to predict preterm birth. Int J Gynaecol Obstet. 2016;135(1):47-50.

15. Hezelgrave NL, Kuhrt K, Cottam K, Seed PT, Tribe RM, Shennan AH. The effect of blood staining on cervicovaginal quantitative fetal fibronectin concentration and prediction of spontaneous preterm birth. Eur J Obstet Gynecol Reprod Biol. 2017;208:103-8.

16. Hezelgrave NL, Abbott DS, Radford SK, Seed PT, Girling JC, Filmer J, et al. Quantitative fetal Fibronectin at 18 weeks of gestation to predict preterm birth in asymptomatic high-risk women. Obstet Gynecol. 2016;127(2): 255-63.

17. Centra M, Coata G, Picchiassi E, Alfonsi L, Meniconi S, Bini $\mathrm{V}$, et al. Evaluation of quantitative fFn test in predicting the risk of preterm birth. J Perinat Med. 2017;45(1):91-8.

18. Bruijn MM, Kamphuis EI, Hoesli IM, Martinez de Tejada B, Loccufier AR, Kühnert M, et al. The predictive value of quantitative fibronectin testing in combination with cervical length measurement in symptomatic women. Am J Obstet Gynecol. 2016;215(6):793.e1-793.e8.

19. Bruijn MM, Hermans FJ, Vis JY, Martinez de Tejada B, Loccufier AR, Kühnert M, et al. Which factors contribute to false-positive, false-negative, and invalid results in fetal fibronectin testing in women with symptoms of preterm labor? Am J Perinatol. 2017;34(3):234-9.

20. Tanır HM, Sener KT, Yildiz Z. Value of Pre-Induction Cervical Fetal Fibronectin (FFN) Assessment as A Predictor of Succesful Vaginal Birth in Nulliparas Undergoing Labor Induction. Gynecol Obstet Reprod Med. 2008;14(3):150-3. 